\title{
Using Supplementary Materials in the Teaching of English: Pedagogic Scope and Applications
}

\author{
Vijay Singh Thakur ${ }^{1}$ \\ ${ }^{1}$ Department of Languages and Translation, Dhofar University, Salalah, Sultanate of Oman \\ Correspondence: Vijay Singh Thakur, Department of Languages and Translation, Dhofar University, P. O. Box \\ No. 2509, P. C. 211, Salalah, Sultanate of Oman. E-mail: vijay_thakur@du.edu.om
}

Received: October 2, 2015 Accepted: October 30, 2015 Online Published: November 2, 2015

doi:10.5539/elt.v8n12p1 URL: http://dx.doi.org/10.5539/elt.v8n12p1

\begin{abstract}
For many students learning English as a second/foreign language is an uninteresting, dull experience. Quite often teachers present words, sentence patterns, and grammar rules in a very mechanical manner. As a result, people come to think of the teaching of grammar and vocabulary as a monotonous job. But a resourceful, imaginative and creative teacher can always break this monotony using innovative techniques and authentic materials. The present paper is an attempt to demonstrate how jokes, anecdotes, stories and situations, and journalistic cartoons can be effectively exploited as supplementary materials to enliven the classroom atmosphere, ensure better learner motivation and participation, and make the teaching and learning of English an enjoyable, stimulating, and memorable experience.
\end{abstract}

Keywords: ESL/EFL context, supplementary materials, monotony, authentic materials, jokes, anecdotes, crisis stories, editorial cartoons, classroom applications, learner motivation and participation

\section{Introduction}

As language teachers, we often feel that the prescribed textbooks are not sufficient to achieve a variety of purposes involved in language teaching. We often find them inadequate to deal with some or the other area(s) of communicative needs of the learners. The needs, abilities, and learning environments of the students vary from place to place, and even class to class. Thus, it is not always possible for a textbook writer to produce an ideal text book, which may cater to the needs of all the students, domestic or international. This is one reason why there are innumerable textbooks available for language teaching-but each one is insufficient, to some extent, for the purpose. Reality calls for the necessity to bridge the gap using interesting supplementary materials in the classrooms. This will help our students to perform and produce their best work in English.

My attempt, in this paper is to evolve a framework and suggest a repertoire of tasks and activities from which communicative classroom applications could be used and adapted for supporting and strengthening language teaching in the classrooms. It is presented in two major sections. The first part offers a general discussion of the material types that could be exploited, and the second deals with some suggestive descriptions of material-wise tasks and activities for classroom applications.

\section{Material Types}

The list of supplementary materials to be fruitfully used in language teaching can be inexhaustible. Plenty of authentic materials are available around us. There are jokes and proverbs, short stories and anecdotes, cartoons and caricatures, newspaper articles and public speeches, television programmes and films, discussions and debates, and so on and so forth. Such materials, which are not designed for instructional purposes, reflect the authentic and real use of the target language. And, in the teaching of English as a foreign or second language, it is desirable that our students develop the ability to communicate in the target language, i.e. they are able to express their ideas in speech and writing and also understand what they hear from people and read in books. Integrating the use of authentic materials with language skills can be highly useful in developing the communicative competence of learners. The use of authentic materials in the English classes is appealing for yet another good reason. Many teachers can attest to the fact, as Ishihara and Chi (2004) point out, that learners seem to be better motivated about language learning when new and exciting materials are used (p. 30). Thus, by exploiting this natural fascination for new materials and instinctive opposition to routine and monotony, a better 
learner motivation and participation can be ensured.

\section{Some Examples: Tasks and Activities}

In this part of the paper we are going to talk about the use of some authentic materials, and tasks and activities that could be set on such materials.

\subsection{Use of Jokes}

As Patil (1994) remarks, jokes are based on the exploitation of shared background knowledge and values and are used to make the listener feel 'at ease' (p. 142). A speaker can communicate a joke meaningfully only if the hearer shares a common context of understandings, practices and norms, and a common consensus. Understanding of the joke depends on a successful interplay of the speaker's intention and the hearer's interpretation of the joke. The first condition for the comprehension of a joke is that the hearer should be able to understand its basic meaning. Generally, jokes have two parts- the first few utterances form the set up and the final utterance functions as the punch, which contains an element of surprise. It is this surprise relationship between the set up and the punch that produces humour and makes the listener laugh. In fact, the understanding of a joke depends upon our ability to relate to the punch line. Also, to use Sherzer's (1985) remark, 'speech play' and 'verbal art' are the source of pleasure in jokes (p. 219). The recognition of a joke consists in relating the 'said' to the 'unsaid'. This exercise of reading between the lines, as McRae and Boardman (1997) remark, deepens and enriches our thinking and feeling which results in more effective personal expression ( $\mathrm{p}$. vii). And this is what we want to achieve by using jokes in our language classes. But before we do that, let us look at the following two jokes:

1). A refugee couple arrived in the United States several years ago with one dream-to become citizens. Through much red tape and years of study, they were patient and hopeful. Then one day, the husband rushed into the kitchen with the long-awaited good news.

"Anna! Anna!" he shouted. "At last! We are Americans!"

"Fine," replied the wife, tying her apron around him.

"Now you wash the dishes." (From J. M. Braude, 1999, Braude's Treasury of Wit and Humour, p. 37. New Delhi: Jaico Publishing House.)

2). An American tourist on a crowded British train noticed a large tweedy woman whose large tweedy dog was occupying a seat. Politely he asked if the woman would mind moving the dog to the floor. "Leave the dog alone!" the woman snapped.

The American left the compartment, walked the length of the train, but failing to find a seat returned and pleaded with the dog owner again.

"I told you to leave the dog alone," she said.

Angry and frustrated the American reached over, opened the window, tossed the dog out, and sat down in the seat next to the woman.

There was stunned silence; then an elderly Englishman across the aisle looked up over his Times. "You Americans amuse me very much, "he said." In the first place, you eat with the fork in the wrong hand. You drive your cars on the wrong side of the road; and now, by Jove, you have thrown the wrong bitch out of the window." (From A Trainload of Jokes and Anecdotes, p. 12. New Delhi: UBSPD. Compiled and edited by K. R. Vaidyanathan)

Now let us think of some activities that can be set on jokes. The following are some of the possibilities:

1). We can jumble the sentences of a joke and ask the students to reorder them.

2). We can ask our students to identify the set up and punch in the jokes. For this purpose, we can separate the set up and punch line and ask the students to match them.

3). The teacher can ask the students to interpret the jokes in their own words.

4). We may also ask the learners to comment on the language play in the jokes.

5). We can divide the students in groups and ask them to share, discuss, and prepare an effective joke. Then the group leaders can tell their joke to the class. This could be done as a small competitive game in which the group that tells the best joke can be rewarded with a prize.

6). At the end of the group competition, the students may be assigned a take-home task to write down all these jokes in their native language. 
7). We can ask them to remember some good jokes in their first language and write them in English.

8). We can motivate our students to collect jokes from various sources and compile a small joke book as their portfolio development work.

9). The teacher can plan 'read and draw', role-play and drama activities on jokes.

Through such tasks/activities we can create a stress-free environment in the classroom and develop and strengthen the skills and strategies of sharing, discussing, memorizing, interpreting, translating, writing, etc.

\subsection{Use of Anecdotes}

Anecdotes are short, interesting or amusing stories about a real person or event. These stories are generally simple and easy to understand. Anecdotes are designed to launch or promote a moral or an ethical issue, which is generally implied in the climax of the story. The moral of the story can be understood only by reading between and beyond the lines. Such an exercise activates and enriches the students' thinking, feeling, and sensibilities. At the same time, such stories lead to pleasure and understanding. For these two reasons, anecdotes could be used as an effective source material in the teaching of English.

First, let us read an interesting anecdote:

There was a man who made living selling balloons at a fair. He had all colours of balloons including red, yellow, blue, and green. Whenever business was slow, he would release a helium-filled balloon into the air and when children saw it go up, they all wanted to buy one. They would come up to him, buy a balloon, and his sales would go up again. He continued this process all day. One day, he felt someone tugging at his jacket. He turned around and saw a little boy who asked, "If you release a black balloon, would that also fly?" Moved by the boy's concern, the man replied with empathy, "Son, it is not the colour of the balloon; it is what is inside that makes it go up." (From Shiv Khera, 1998, You Can Win, p. 2. India: Macmillan.)

The highlight of this anecdote lies in its moral. The moral of the story is that all human beings are equal, that racial discrimination is man-made.

We can ask our students the following questions on this anecdote:

1). What does this story teach us? Explain in your own words. Substantiate the answer with examples. (This can be an individual or group activity.)

2). Identify the utterances that suggest the moral in the story.

3). Could you suggest a suitable title for the story?

4). Do you agree that the moral has been presented effectively? Discuss.

5). Have you ever wondered why some individuals, organizations, or countries are more successful than others? Discuss your reasons in the light of this story. (This task could also be done as an individual or a group activity.)

6). Do you remember any interesting anecdote you have heard or read? Share it with the class.

7). Try to recollect a memorable incident or event and try to write a meaningful anecdote on it. (This could be assigned as a homework task and the students could be asked to share it with their friends by exchanging and reading each other's work.)

8). Anecdotes can be effectively used for the purposes of cloze tests.

9). They can also be used for role-play and drama activities.

I might argue here that the language work done through anecdotes would not only result in the development of communicative competence of the learners but also in training them to develop original and fresh ideas.

\subsection{Use of Stories and Situations of Crisis}

Research in the last three decades (e.g. Rivers, 2000; Well's et al., 1981; Rose \& Nicholl, 1997) and our experience as EFL/ESL professionals suggest that the goal of developing communicative competence of our learners may be better achieved by involving them in learner-friendly interactive activities. Some stories and situations involve complicated crisis/crises, and demand from the learners an analysis of the situation and the best possible solutions with proper justifications. As a result, they prove to be a very effective mode of teaching and practising English language and critical thinking skills.

Let us examine the following story, which involves decision-making. Here is the story followed by the task: 


\subsection{Lifeboat}

An ocean-liner sank at sea, and seven people escaped in a lifeboat. Unfortunately, the lifeboat only has enough room and supplies for five people. Therefore two people will have to abandon the lifeboat. The ocean contains hungry sharks, so those people who have to leave the boat will die. (Source: Thakur, 2013, p. 188-89)

You must select the two people who will have to be sacrificed. Justify the reason why you picked these two and also justify the reason why the other five should live. To help you make your selection, the following information is presented.

1). A one-year-old baby that is travelling with its grandmother. The baby is extremely sick, suffering from a rare but possibly treatable disease.

2). The baby's 55 -year old grandmother. She is in good health but has been depressed since the death of her husband.

3). The captain of the ocean-liner. He is 31 years old and has 10 children. His wife is dead. He has no insurance.

4). A 42-year old pregnant woman. Gossip on the ship indicates that she may be a woman of loose character. Her heavy make-up and vulgar language seem to indicate the gossip is true.

5). A 70-year old scientist. He was one of the original developers of the atomic bomb, which was dropped on Japan during World War II. His recent research might possibly lead to a cure for lung cancer in the next year or two.

6). A 21-year old university student. He is All-American football player. He is extremely brilliant and has an I.Q. of 170 . He has spent one year in prison for refusing to join the army.

7). A 72-year old doctor who is a specialist in rare childhood diseases. Some people think he is a saint. But most of them don't know he is a drug addict. The police are investigating him because there is evidence that he sells drugs to young people.

After reading the above story the students can be actively involved in giving reasons for their choices and others can be allowed to give their counter arguments against the reasons given for the choices. Then the participants can refute the counter arguments by giving further stronger argument(s). Thus the debating continues.

By using such stories and problem-solving tasks both as individual and group work and for oral and written work we can exploit the richness of the material as well as the interactive approaches. Our main aim in doing so is to involve the learners in active interaction. Such an exercise corresponds with Rose and Nicholl's (1997) research findings, which suggest that the production of knowledge requires the use of a number of thinking skills such as analytical, lateral, problem-solving, critical, creative and reflective thinking. This story and the task also have the rationale for critical thinking as an underlying principle. Critical thinking is one of the thinking skills that should be highlighted in designing and improving language curriculum (Üstünlüolü, 2004, p. 3) because the world we live in is getting more complicated, and information processing has become more important than before (Van Duzer \& Florez, 1999). Taking this idea into consideration, language teachers can encourage students to go beyond surface meaning and discover the deeper meaning.

\subsection{Use of Editorial Cartoons}

Cartoons are drawings that exaggerate some physical feature, action, or quality of a person or thing depicted and they are popular with people of all ages. The central idea of a cartoon may vary from that of simply wanting to amuse us to that of influencing our thinking. The humour, empathy, and satire created in cartoons enable us to better understand the world. We can use cartoons to teach language, human values, ethics and citizenship. Lots of information is packed in a small picture presented with or without a short caption. Such pictures create a powerful ground for the readers to interpret, discuss, and present their viewpoint. Thus, newspaper cartoons can be used as an effective tool for teaching critical thinking and promoting higher order skills. The visual elements, with or without a caption, in a cartoon give us a bunch of starting points for discussion and could be used as a springboard for any amount of language work.

Smith (1993) remarks that students can always understand a visual image, and even laugh about it, whatever their language level (p. 58). Patil's (1996) comment that the students enjoy working on cartoons because cartoons are an inexhaustible resource of fun and humour (p. 22) is also significant for us as language teachers. The use of cartoons is one important way to ensure learner motivation and participation. An imaginative and resourceful teacher can work wonders with the help of cartoons. Then, why not bring the power of cartoons-the strength of their images and the force of their messages-into our classrooms. But, before exploring various possibilities of language work through them, it is worthwhile to see some interesting cartoons. The two cartoons that follow are 
by a famous cartoonist named Laxman, a leading cartoonist who has drawn hundreds and thousands of cartoons for The Times of India:

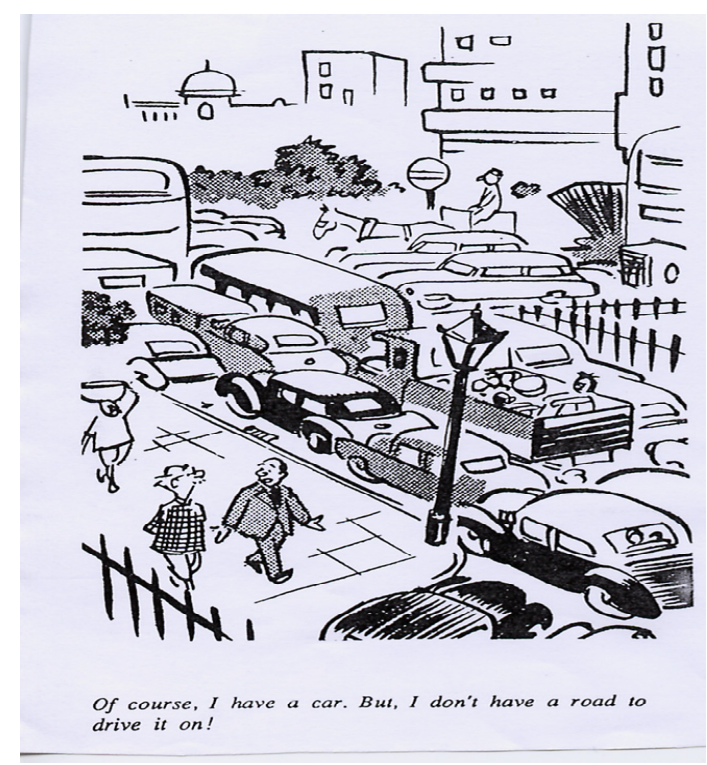

$\mathrm{C} 1$

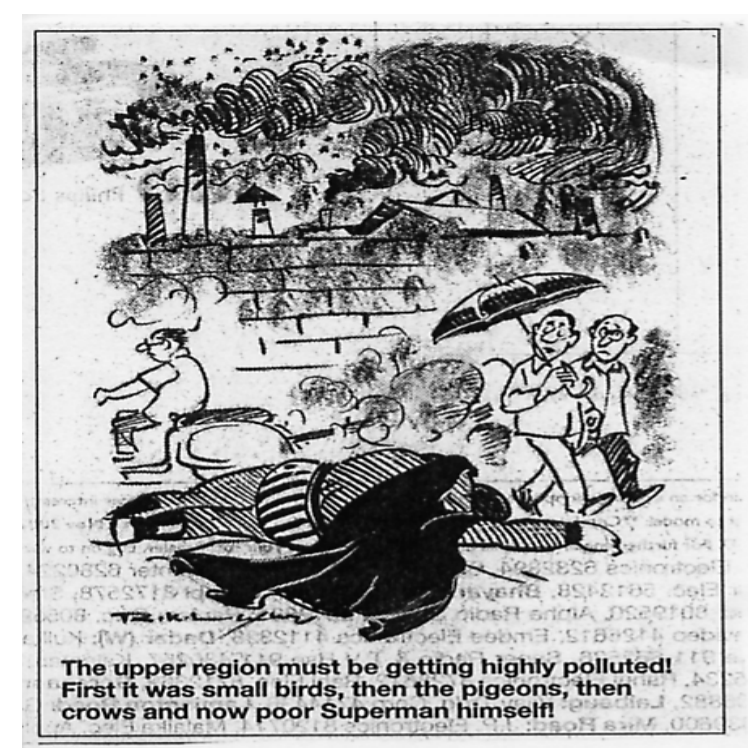

$\mathrm{C} 2$

We can set a number of tasks on such cartoons. These are some of the possibilities:

1). The pictures and the captions can be separated and the students could be asked to match them. (We can use 6 to 8 such cartoons for this task, which could be a warm-up activity.)

2). The key words can be blanked out and the students may be asked to guess the missing words and predict their meaning in the context.

3 ). We can ask our students to talk about the central idea or theme of cartoons and also about their humorous and serious aspects. They could also be asked to discuss the effectiveness of these aspects of cartoons.

4). Students may be asked to discuss and analyze cartoons in groups and even to create them as their original works that reflect their perception of the current events and cultural trends.

5). We can ask the students to create an effective title for a cartoon and then write a brief essay on that topic.

6). Students could be motivated to discuss the problem depicted in the cartoon (for example, as in the two cartoons included here) and also to express their views about how that problem could be solved. They can do this in writing or in speech.

7). We may even involve students in debating the cartoonist's viewpoint. Many of them may not agree with it and can come out with a different perception and position on the issue.

Thus, cartoons can be a rich resource for teaching higher-level thinking skills. They can help develop students who are much more sophisticated interpreters of current events than students of previous generations. Today's students, in a globalized world, are ready to look beyond actual events and immerse themselves in the issues of concern. This suggests that it is a better time for teachers to incorporate editorial cartoons into their teaching materials.

\section{Conclusion}

In this paper I have discussed the need and modes of using supplementary authentic materials for the purposes of language teaching, which has been demonstrated by taking into account four types of authentic materials, viz. jokes, anecdotes, crisis stories, and editorial cartoons. The perspective, developed through a multi-level discussion of these materials and the corresponding tasks and activities, suggests that the use of authentic materials has a definite place in language learning in ESL/EFL context. The paper claims that the use of such supplementary materials provides the basis for the use of meaningful real language through interesting contents and extended contexts, which enables the learners to become more motivated and active in learning the target 
language and willingly participating in it. Once learners gain confidence through understanding and enjoying these authentic materials they feel prepared to view such other materials on their own and a new venture into more and more authentic language begins. The paper also displays a key advantage of teaching language through such materials in enabling the learners to recognize a wide range of subjective analyses, to develop self-awareness, and to see linkages and complexities they might otherwise miss. Put more meaningfully, teaching this way we will succeed in producing learners who build on prior knowledge and use critical thinking skills to achieve higher levels of knowledge. Thus, the strategic use of authentic materials in the teaching of English will help us keep the curriculum relevant and meet the needs of today's learners.

\section{References}

Ishihara, N., \& Chi, J. C. (2004). Authentic video in the beginning ESOL classroom: Using a full-length feature film for listening and speaking strategy practice. Forum, 42(1), 30-35.

Laxman, R. K. (1998). The best of Laxman: C1, India: Penguin Books.

Laxman, R. K. (2002). Passing thought: C2. In The Times of India, 13 Oct.

McRay, J., \& Boardman, R. (1977). Reading between the lines. India: Cambridge University Press.

Patil, Z. N. (1994). Style in Indian English fiction: A study in politeness strategies. New New Delhi: Prestige Books.

Patil, Z. N. (1996). Using cartoons in the teaching of English. Journal of English and Foreign Languages, 17, $15-26$.

Rivers, W. M. (2000). Interaction as the key to teaching language for communication. In W. M. Rivers (Ed.) Interactive Language Teaching (pp. 3-16). Cambridge: Cambridge University Press.

Rose, C., \& Nicholl, M. J. (1997). Accelerated learning for the 21st century. New York: Dell Publishing.

Sherzer, J. (1985). Puns and jokes. In T. A. V. Dijk (Ed.) Handbook of discourse analysis, 3, 213-21.

Smith, J. (1993). Cartoons in class. Practical English Teaching, June, 58-59.

Thakur, V. S. (2013). Engaging learners in productive learning: Some pedagogical gateways. In Z. N. Patil, S. Marathe, \& A. Patil (Eds.), Aspects of ELLT: Essays on Theory, Practice and Experimentation in English Language and Literature Teaching in India and Elsewhere (pp. 185-204). Hyderabad: The English and Foreign Languages University.

Üstünlüolü, E. (2004). Language teaching through critical thinking and self-awareness. Forum, 42(3), 2-7.

Van Duzer, C., \& Florez, M. C. (1999). Critical literacy for adult English language learners. In ERIC Digest, EDOLE 9907, Washington, D.C.: National Center for ESL Literacy Education.

Wells, G. (1981). Learning through interaction: The study of language development. Cambridge: Cambridge University Press. http://dx.doi.org/10.1017/CBO9780511620737

\section{Copyrights}

Copyright for this article is retained by the author(s), with first publication rights granted to the journal.

This is an open-access article distributed under the terms and conditions of the Creative Commons Attribution license (http://creativecommons.org/licenses/by/3.0/). 